\title{
Analytical and Biological Evaluation of Two Schiff's Bases: Spectrophotometeric Analysis of Copper (II) in Water and Soil Samples
}

Bhajanthri Natesh Kumar ${ }^{1}$, Suvardhan Kanchi ${ }^{2}$, Krishna Bisetty ${ }^{2}$ and Nimmagadda Venkata Vijaya Jyothi ${ }^{*}$

${ }^{1}$ Department of Chemistry, Sri Venkateswara University, India

${ }^{2}$ Department of Chemistry, Durban University of Technology, South Africa

\begin{abstract}
Two novel ligands, (E)- $N^{1}$-(2-hydroxy-5-nitrobenzlidene) isonicotinoylhydrazone (HNBISNH)/2-(4-fluoro benzlideneamino)benzenethiol (FBBT) were synthesized and used for the quantification of copper (II) in various water and soil samples. HNBISNH/FBBT interacts with copper (II) to form 1:1 [L:M] orange /brick red color complexes in presence of phosphate buffer of $\mathrm{pH} 3.7 / 4.5$ which increases the sensitivity of the complexes. Thus formed colored complex followed the Beer's law up to 1.6 and $1.9 \mathrm{mg} \mathrm{L}^{-1}$ with an optimum concentration range over $0.11-1.3 \mathrm{mg} \mathrm{L}^{-1}$ and $0.10-1.7 \mathrm{mg} \mathrm{L}^{-1}$, the slope of Ringbom's plot are found to be 0.3500 and 0.3300 for copper(II)-HNBISNH and copper(II)-FBBT complexes, respectively. The molar absorptivity and Sandell's sensitivity of copper (II)-HNBISNH and copper(II)-FBBT complexes were calculated and found to be $4.91 \times 10^{4} \mathrm{~L} \mathrm{~mol}^{-1} \mathrm{~cm}^{-1}, 6.1 \times 10^{4} \mathrm{~L} \mathrm{~mol}^{-1}$ and $0.0010 \mu \mathrm{g}$ $\mathrm{cm}^{-2}$ and $0.0014 \mu \mathrm{g} \mathrm{cm}^{-2}$ respectively. The detection limits was calculated and found to be $0.043 \mu \mathrm{g} \mathrm{L}^{-1}$ and $0.036 \mu \mathrm{g}$ $\mathrm{L}^{-1}$ with $\mathrm{HNBISNH}$ and FBBT respectively. Various optimum conditions such as effect of $\mathrm{pH}$, reagent concentration, accuracy, precision and reproducibility were investigated to improve the sensitive for the present method. The detailed study of various excipients confirmed the high selectivity of the method. The proposed method was applied to the determination of copper (II) in different water \& soil samples obtained results were in good agreement with atomic absorption spectrometric method (AAS).
\end{abstract}

Keywords: (E)-N $N^{1}$-(2-hydroxy-5-nitrobenzlidene) isonicotinoyl hydrazone (HNBISNH); 2-(4-fluoro benzlideneamino) benzenethiol (FBBT); Copper (II); Spectrophotometry; Biological activity; Environmental samples

\section{Introduction}

Copper is an essential trace nutrient to all high plants and animals. In animals, including human it is found in primarily in the bloodstream, and in copper-based pigments. However, insufficient amounts; copper can be poisonous and even fatal to organisms. Copper also has a significant presence as a decorative metal art. It can also be used as an anti-germ surface that can add to the antibacterial and antimicrobial feature of buildings such as hospitals [1]. Copper has a high electrical and thermal conductivity, among pure metals at room temperature [2]. On the other hand, toxic rule of the metal ion is well recognized [3]. Heterocyclic azodyes have been used as chromogenes in spectrophotometric determination of copper (II) ions. These azodyes are 2-amino-5-bromopyridylazo resorcinol [4], 1-[pyridyl 2-azo]-naphthol (PAN) [5,6], and its derivatives are 1-(2-thiazolylazo)-2-naphthol [7], 1-(5 bromo-2-pyridylazo)-2naphthol-6-sulphonic acid [8], 2,6-bis(4-sulfo-1-hydroxy-2 naphth alazo) pyridine [9], 4-(1H-pyrazolo 3,4-d $\}$ pyrimidin-4-ylazo) benzene1,3-diol [10], 4-(p-Nitrophenylazo)-2-amino-3-pyridinol [11], 1-(2quinolylazo)-2,4,5 trihydroxybenzene [12], bromosulphonazo III [13] and alizarin red S [14]. These dyes are highly sensitive but lack of the selectivity. The coordination chemistry of hydrazones is an intensive area of study of numerous transition metals. Hydrazones have been studied as a group of most useful spectrophotometric reagents. The short comings of hydrazones were the lack of selectivity for metal ions, therefore much work have been devoted to the development of masking agents for use of hydrazones. Among these some of the hydrazone are 2,2'-dipyridyl-2-pyridylhydrazone [15] and 2-pyridine carboxaldehyde isonicotinyl hydrazone [16]. Many techniques such as Atomic Absorption Spectrophotometry [17], Inductively Coupled Plasma Atomic Emission Spectroscopy [18], Voltammetry [19] and Spectrophotometry $[20,21]$ have been reported for the determination of copper (II).
The aim of the present work was to provide a facile, sensitive and rapid non-extractive spectrophotometric method for the determination of trace amounts of copper (II) in different sample of environmental importance. In this study, new analytical reagents (E)- $\mathrm{N}^{1}-(2$-hydroxy5-nitrobenzlidene) isonicotinoyl hydrazone (HNBISNH) and 2-(4-fluorobenzlidene amino) benzenethiol (FBBT) was successfully synthesized for the determination of copper (II) in environmental samples.

\section{Experimental}

\section{Instrumentation}

A HITACHI model U 3400 UV VIS NIR Spectrophotometer with $10 \mathrm{~mm}$ stopped glass cells was used. An ELICO model Li-129 was used for all $\mathrm{pH}$ measurements.

\section{Reagents}

All reagents used were of analytical reagent grade and solutions were prepared with deionized distilled water unless mentioned. A phosphate buffer solution prepared by adding: $50 \mathrm{~mL}$ of $0.25 \mathrm{M}$ disodium hydrogen orthophosphate (SD fine Chemicals, India) dissolved in $20 \mathrm{~mL}$ of $0.1 \mathrm{M}$ phosphoric acid (SD fine Chemicals, India) and $\mathrm{pH}$ was adjusted to 4.0/4.7 with $0.25 \mathrm{M}$ disodium hydrogen orthophosphate solution and diluted to $100 \mathrm{~mL}$ in a volumetric flask.

${ }^{*}$ Corresponding author: Nimmagadda Venkata Vijaya Jyothi, Department of Chemistry, Sri Venkateswara University, Tirupati-517 502, A.P, India, Tel: 919912366219; E-mail: nvvjyothi73@gmail.com

Received January 27, 2014; Accepted March 10, 2014; Published March 12 2014

Citation: Natesh Kumar B, Kanchi S, Bisetty K, Vijaya Jyothi NV (2014) Analytical and Biological Evaluation of Two Schiff's Bases: Spectrophotometeric Analysis of Copper (II) in Water and Soil Samples. J Environ Anal Chem 1: 106. doi:10.4172/10.4172/2380-2391.1000106

Copyright: (C) 2014 Natesh Kumar B, et al. This is an open-access article distributed under the terms of the Creative Commons Attribution License, which permits unrestricted use, distribution, and reproduction in any medium, provided the original author and source are credited. 


\section{Synthesis of ligands}

Preparation of (E)-N $\mathrm{N}^{1}$-(2-hydroxy-5-nitrobenzlidene) isonicotinoyl hydrazone (HNBISNH): Accurately weighed $1.2 \mathrm{~g}$ of 2-hydroxy-5-nitrobenzaldehyde and $0.822 \mathrm{~g}$ of isonicotinoyl hydrazide were transferred into a $50 \mathrm{~mL}$ round bottom flask. Ethyl alcohol was used as solvent and the condensation process was carried out about $2 \mathrm{~h}$ at $60^{\circ} \mathrm{C}$. The yellow colored product of HNBISNH was formed and further subjected to evaporate the solvent and collected the pure solid compound with yield about $1.98 \mathrm{~g}(86 \%)$. The melting point of HNBISNH was found to be in the range of $214-216^{\circ} \mathrm{C}$ with solubility in DMF. The preparation pathway of color forming ligand was shown in Scheme 1a.

Preparation of 2-(4-fluorobenzlideneamino) benzenethiol (FBBT): The physical state of 2-aminobenethiol was semi solid while 4-fluorobenzaldehyde was colorless oily liquid. Both reactants density values were taken into consideration for the synthesis of product. Since those two reactants are nearly liquids accurately measured 0.48 $\mathrm{mL}$ of 2 -aminobenethiol and $0.48 \mathrm{ml}$ of 4 -fluorobenzaldehyde were transferred into a $50 \mathrm{~mL}$ round bottomed flask and methanol was used as a solvent. Reflux the reaction mixture for about $1 \mathrm{~h}$ at $60^{\circ} \mathrm{C}$. Pale yellow colored oily product was formed and further subjected rotor to expel the excess of solvent and obtained the pure product. This product on long standing in ambient temperature converted to yellow solid. The melting point was in the range of $202-204^{\circ} \mathrm{C}$ with solubility in hexane. The reaction procedure of color forming ligand was shown in Scheme 1b.

\section{Preparation of standard solutions}

$2.86 \mathrm{~g}$ of HNBISNH and $2.31 \mathrm{~g}$ of FBBT was dissolved in deionized distilled water and diluted to $100 \mathrm{~mL}$ to get $0.1 \mathrm{M}$ of stock solution. Working solution of HNBISNH and FBBT were prepared by appropriate dilution and the solutions were stable for several months. A stock solution of copper (II) $\left(1.0 \mathrm{mg} \mathrm{mL}^{-1}\right)$ was prepared by dissolution of $0.250 \mathrm{~g}$ copper sulphate pentahydrate (SD fine Chemicals, India) in $100 \mathrm{~mL}$ standard flask and further dilutions as required were employed.

\section{General procedure}

In the first step an aliquot containing not more than 1.0-100 $\mu \mathrm{g}$ $\mathrm{mL}^{-1}$ of copper (II) was transferred into $25 \mathrm{~mL}$ calibrated flask, $3.0 \mathrm{~mL}$ of $0.005 \mathrm{M}$ HNBISNH and $5 \mathrm{~mL}$ of phosphate solution with $\mathrm{pH} 4.0$ solution were added successively and the mixture was diluted up to the markwith deionized distilled water. The first step was repeated for second ligand, FBBT as well. The appearance of the orange and brick red color chromophores was instantaneous and absorbance was measured at $480 \mathrm{~nm}$ and $520 \mathrm{~nm}$ against reagent blank solution. The reagent blank was prepared in a similar manner without copper (II). All measurements were carried out at ambient temperature. The copper(II) content in an unknown sample was determined using a calibration graph.

\section{Procedure for evaluation of biological activity of complexes}

To a methanolic solution of copper (II) sulphate, a hot methanolic Solution of the HNBISNH/FBBT ligand was added slowly with stirring. The mixture was refluxed on a hot water bath. It was concentrated under reduced pressure to two-third the original volume and cooled. The solid that separated out was filtered, washed with water, hot methanol and ether and was vacuum dried to obtain solid complexes.

Antibacterial activity of the two synthesized complex compounds was determined with gram positive organisms (Bacillus subtillis and
Staphylococcus aureus) and gram negative organisms (Escherichia coli and Pseudomonas aeruginosa) using disc diffusion method [22]. The Muller-Hinton agar was rigorously tested for the composition and $\mathrm{pH}$. Further, the depth of the agar in the plate was a factor to be considered in the disc diffusion method. The test plates were prepared by $0.5 \mathrm{~mL}$ of standard inoculums pipetted into a sterile petri plate; $20 \mathrm{~mL}$ of melted agar medium was then added to $10 \mathrm{~cm}$ petri plate and mixed well by gently swirling on the table top. The seeded plates are allowed to solidify and $10 \mu \mathrm{g} \mathrm{mL}^{-1}$ of complex compounds was impregnated on sterilized filter paper disc was carefully transferred in the agar plates. The chemical diffuses from the disc into the agar and place the chemical only around the disc. The solubility of the chemical and its molecular size was determined using the chemical infiltration size around the disc.Standard disc of Gentamycin $10 \mu \mathrm{g}$ (antibacterial agent) was served as positive controls for antimicrobial activity on the agar plates. The plates were incubated at $37^{\circ} \mathrm{C}$ for $24 \mathrm{~h}$ around the disc opaque area indicates that the compound, which diffused into the agar from the disc, which inhibits the growth of the organism. The inhibition Zone (IZ) was recorded with the help of scale, and compared with control containing standard antibiotic Gentamycindisc. The experiment was triplicated and the mean values are presented along with the standard deviation. Minimum Inhibitory Concentrations were determined by the Vollekova and Usman two fold dilution method $[23,24]$.

\section{Sample preparation}

Procedure for water samples: One liter of the water sample collected from various sites outside the Tirupati city were acidified with hydrochloric acid and filtered with a $0.45 \mu \mathrm{m}$ filter. The samples were pre-heated and evaporated to $250 \mathrm{~mL}$. The copper (II) contents were determined according to aforesaid procedures. The obtained results were compared with standard atomic absorption method in terms of student's ' $t$ '-test and variance ratio ' $f$ ' -test.

Procedure for soil samples: Soil samples collected from industrial areas surrounding Tirupati city were accurately weighed $(2.0 \mathrm{~g})$ in a 100 $\mathrm{mL}$ beaker. The content was digested as per to the reported method, [25] then $10 \mathrm{~mL}$ concentrated $\mathrm{HNO}_{3}$ and $2.0 \mathrm{~mL}$ of $70 \% \mathrm{HClO}_{4}(\mathrm{v} / \mathrm{v})$ was added and heated for $1 \mathrm{~h}$. The mixture was filtered through a Whatman No. 40 filter paper into a $250 \mathrm{~mL}$ calibrated flask and its $\mathrm{pH}$ was adjusted to desired value and diluted to mark with deionised water. In all of real and synthetic amount of copper (II) ion was found by standard addition method.

\section{Results and Discussion}

\section{Absorption spectra}

Under the optimal experimental condition, the absorption spectra of HNBISNH/FBBT and copper (II)-HNBISNH/FBBT complexes were scanned. The absorption maximum of reagent blanks HNBISNH/ FBBT, were measured at $370 \mathrm{~nm}$ and $395 \mathrm{~nm}$, whereas copper (II)HNBISNH/FBBT complexes gave an absorption peak at $460 \mathrm{~nm}$ and $530 \mathrm{~nm}$. The difference (bathochromic shift) of the two peaks was $90 \mathrm{~nm}$ and $145 \mathrm{~nm}$, and could be obviously distinguished. Thus, the absorption peaks at $460 \mathrm{~nm}$ and $530 \mathrm{~nm}$ were chosen as the determination of wave length for copper (II)-HNBISNH/FBBT complexes as illustrated in Figure 1.

\section{Effect of $\mathbf{p H}$}

$\mathrm{pH}$ studies were carried out on the peak height of copper (II)HNBISNH/FBBT complexes at various concentrations (0.001-0.10M) by fixing $0.005 \mathrm{M}$ HNBISNH and FBBT concentration. The $\mathrm{pH}$ of 
phosphate buffer was changed over a range of 2.0-7.0 and the peak height were measured for each concentration level of copper (II). At all concentration levels of copper (II)-HNBISNH/FBBT complexes, maximum absorbance were found between $\mathrm{pH} 3.0$ and 5.0. Therefore, a pH 3.7 for HNBISNH and 4.5 for FBBT of phosphate buffer system was chosen throughout the study as shown in Figure 2.

\section{Effect of ligand concentration on absorbance}

The effect of concentrations of both ligands (HNBISNH and FBBT), on the peak height was investigated at $\mathrm{pH} 3.7$ and 4.5 in a phosphate buffer system. The concentrations of HNBISNH and FBBT was varied over the range $0.001-0.10 \mathrm{M}$. Maximumpeak height was obtained at a concentration of $0.04 \mathrm{M}$ for HNBISNH and 0.01 M FBBT as color developing reagents for lower concentration level of copper (II) in the sample solution. Further, increase in HNBISNH and FBBT concentration, slight decrease in the peak height was observed. Hence, $0.04 \mathrm{M}$ for HNBISNH and 0.01 M FBBT was optimized for all further studies as represented in Figure 3.

\section{Effect of time and temperature on absorbance}

The reaction was instantaneous for the both complexes, but these systems attained maximum and constant absorbance just after the dilution to volume ( $25 \mathrm{~mL}$ in volumetric flask) at room temperature

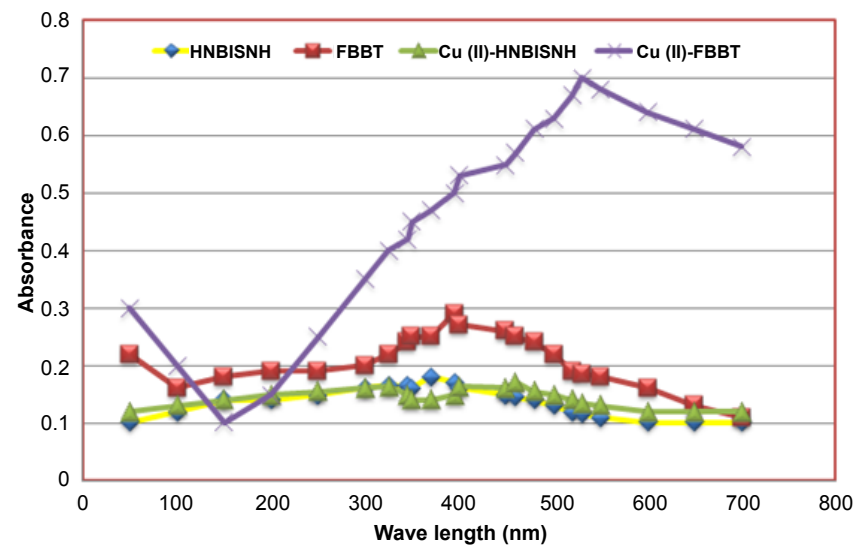

Figure 1: Absorption spectra for copper (II)-HNBISNH/FBBT complexes against reagent blank (Optimum conditions:- $\mathrm{pH}: 3.7 / 4.5$, Ligand concentration:0.04/0.01M, Temperature: $32 \pm 5^{\circ} \mathrm{C}$ ).

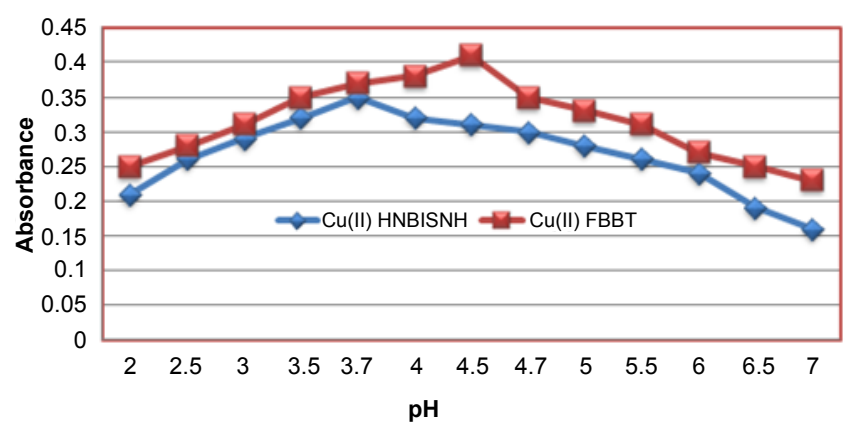

Figure 2: Effect of $\mathrm{pH}$ on the absorption of copper (II) complexed with HNBISNH and FBBT (Optimum conditions:- Ligand concentration:0.04/0.01M, Temperature: $32 \pm 5^{\circ} \mathrm{C}$ ).

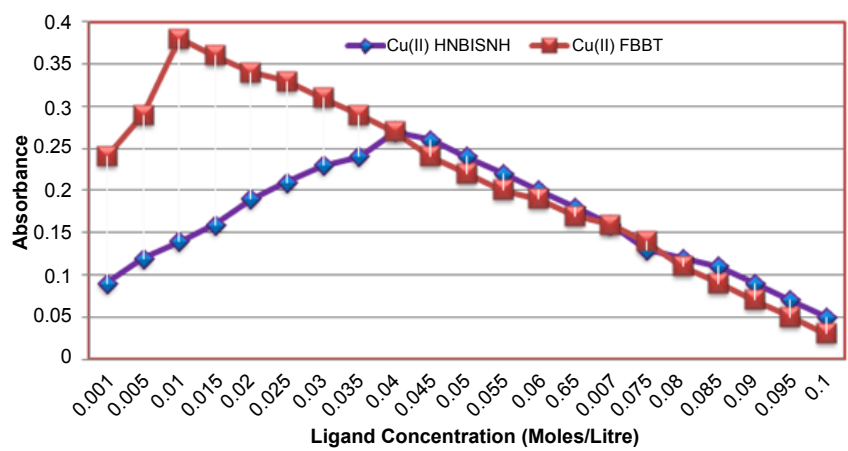

Figure 3: Effect of ligand concentration on the absorption of copper (II) complexed with HNBISNH and FBBT (Optimum conditions:- $\mathrm{pH}: 3.7 / 4.5$, Temperature: $32 \pm 5^{\circ} \mathrm{C}$ )

$\left(32 \pm 5^{\circ} \mathrm{C}\right)$ and remained stable for $30 \mathrm{~h}$ and $60 \mathrm{~h}$ for copper (II)HNBISNH/FBBT complexes, respectively.

\section{Stability of the chromophoric system}

After mixing all the components, the absorbance related to both complexes reached its maximum in less than $1 \mathrm{~min}$ at ambient temperature and remain stable for $30 \mathrm{~h}$ [copper (II)-HNBISNH] and 60h [copper (II)-FBBT] in aqueous solution. Due to stability of the complex and clarity of complex solution, the extraction step was omitted to reduce usage of environmental hazardous solvents, which made the method eco-friendly.

\section{Composition of the complexes}

The stoichiometry of the complexes was identified using the molar ratio at the optimum conditions discussed above. Figures $4 \mathrm{a}$ and $4 \mathrm{~b}$ show that maximum absorption was found to be at molar ratio 1.0 by varying the concentrations of HNBISNH and FBBT, representing the interaction of one ligand molecule with metal in the complex formation. Accordingly, the results indicated that the stoichiometric ratio was (1:1) [M:L]. The composition of the both complexes [copper (II)-HNBISNH/FBBT] were determined using Job's continuous variation method indicates the formation of 1:1 (M:L) complexes.

\section{Ringbom plot's for copper (II)-HNBISNH/FBBT complexes}

Ringbom's plot is the standard protocol adopted to know the optimum range of concentration for chromophoric system that obeys Beer's law. The plots were drawn between $\log C$ of copper (II) and (1$T$ ) (where $T$ is the transmittance). The plots was sigmoid shape with a linear segment at intermediate absorbance values $0.1-1.0,0.2-1.6$ and concentration values $1.20-3.1 \mu \mathrm{g} \mathrm{mL}^{-1}$ and $1.22-3.4 \mu \mathrm{g} \mathrm{mL}^{-1}$ for copper (II)-HNBISNH and copper (II)-FBBT respectively. The slope of Ringbom's plot from Figure 5 are found to be 0.3500 for copper (II)-HNBISNH and 0.3300 for copper (II)-FBBT complexes. Hence, the ratio between the relative error in concentration and photometric errors are 2.50, 2.20 for found to be concentration of $0.0250,0.0220$ having $1.0 \%$ photometric error.

\section{Sensitivity and calibration curves}

The complexes obey Beer's law up to 1.7 and $2.0 \mathrm{mg} \mathrm{L}^{-1}$ with an optimum concentration range between $0.11-1.4 \mathrm{mg} \mathrm{L}^{-1}$ and $0.10-$ $1.8 \mathrm{mg} \mathrm{L}^{-1}$ for copper (II)-HNBISNH/FBBT systems respectively. The molar absorptivity of complexes at 460 and $530 \mathrm{~nm}$ and at $\mathrm{pH} 3.7$ and 4.5 was calculated $4.91 \times 10^{4} \mathrm{~L} \mathrm{~mol}^{-1} \mathrm{~cm}^{-1}$ and $6.1 \times 10^{4} \mathrm{~L} \mathrm{~mol}^{-1} \mathrm{~cm}^{-1}$ 
respectively. Sandell's sensitivity for both complexes were found to be $0.0010 \mu \mathrm{g} \mathrm{cm}^{-2}$ and $0.0014 \mu \mathrm{g} \mathrm{cm}{ }^{-2}$ for copper (II)-HNBISNH/FBBT systems respectively. The correlation coefficient $(\gamma)$ for the complexes of copper (II)-HNBISNH/FBBT experimental data was 0.9996 and 0.99998 respectively. The composition of the both complexes [copper (II)-HNBISNH/FBBT] were determined using Job's continuous variation method indicates the formation of 1:1 (M:L) complexes. The stability constants corresponding to copper (II)-HNBISNH/FBBT was determined and found to be $5.9 \times 10^{15}$ and $6.7 \times 10^{15}(1: 1, \mathrm{M}: \mathrm{L})$ respectively. The calibration graphs were obtained at the optimum working conditions as shown in Figures $6 \mathrm{a}$ and $6 \mathrm{~b}$.

\section{Effect of excipients}

To understand the selectivity of the present method using two ligands (HNBISNH/FBBT), the effect of potentially interfering species on the copper (II) determination was studied and carried out by adding a known concentration of excipients to copper (II) solution of 0.2 $\mu \mathrm{g} \mathrm{mL} \mathrm{m}^{-1}$. Several anions and captions were studied in detail. Table 2 summarizes the tolerance limits of interfering ions in the determination of $0.2 \mu \mathrm{g} \mathrm{mL}^{-1}$ copper (II). The tolerance limit was taken as the amount causing an error of $\pm 2 \%$ at the peak height.

\section{Method evaluation}

The proposed method was critically evaluated with regard to reproducibility, accuracy, and detection limit for analysis of copper (II) in various environmental samples.

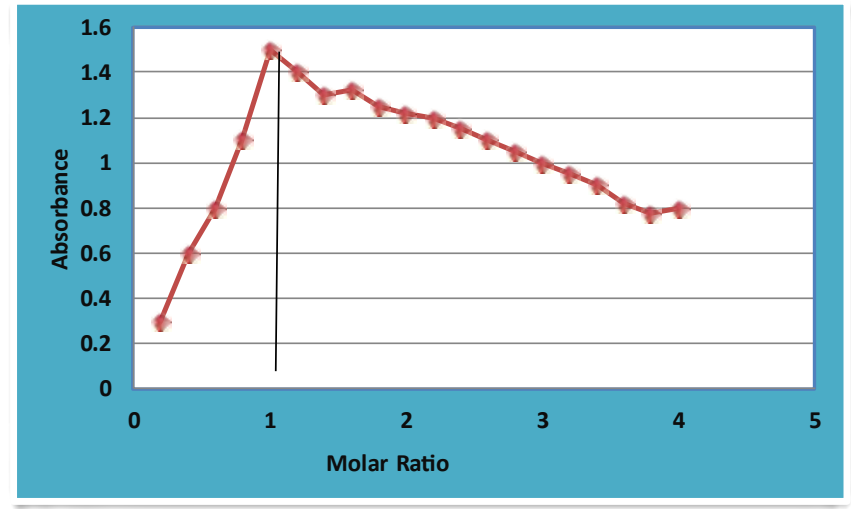

Figure 4a: Molar ratio for copper (II)-HNBISNH complex.

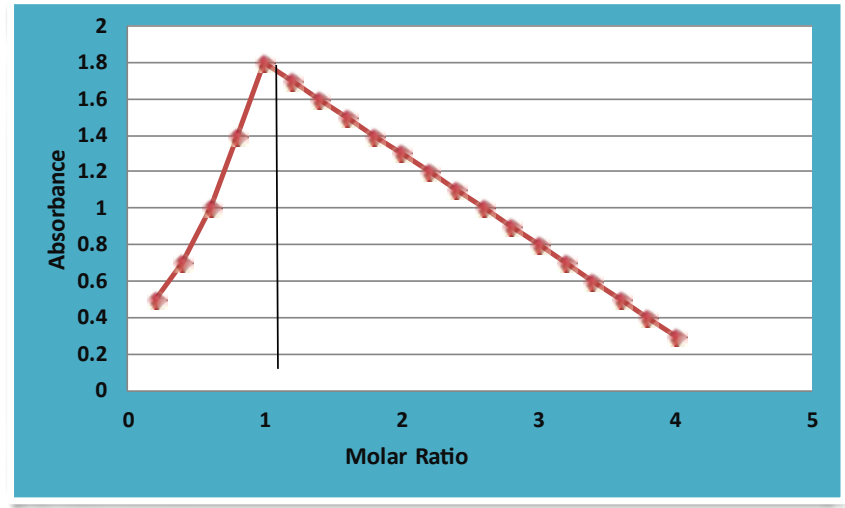

Figure 4b: Molar ratio for copper (II)-FBBT complex.

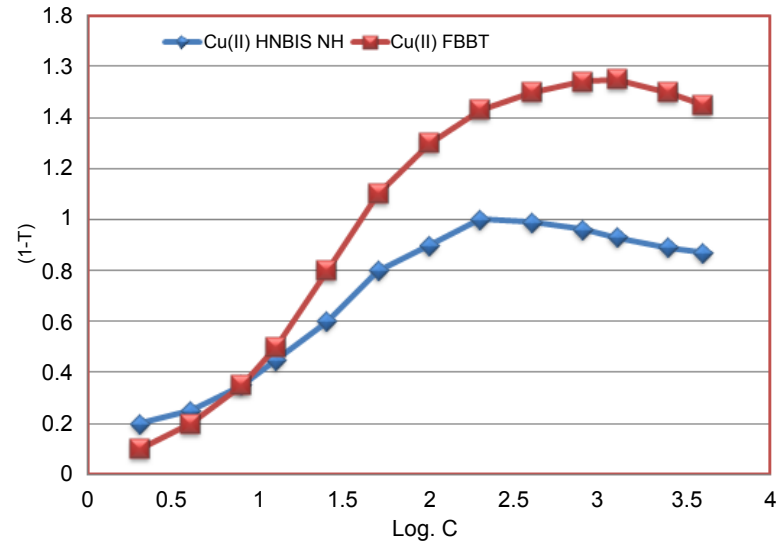

Figure 5: Ringbom plot's for copper (II) complexed with HNBISNH and FBBT (Optimum conditions:- $\mathrm{pH}: 3.7 / 4.5$, Ligand concentration: $0.04 / 0.01 \mathrm{M}$, Temperature: $32 \pm 5^{\circ} \mathrm{C}$ )

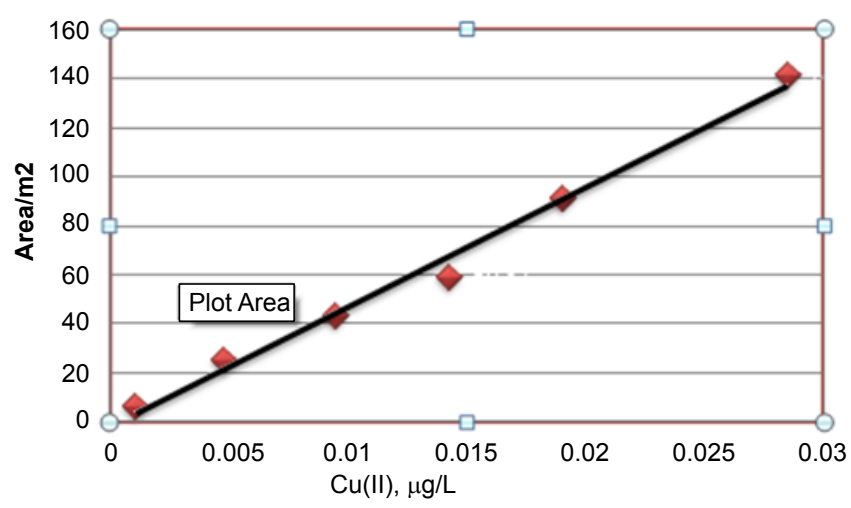

Figure 6a: Calibration plots for the determination of copper (II) with HNBISNH.

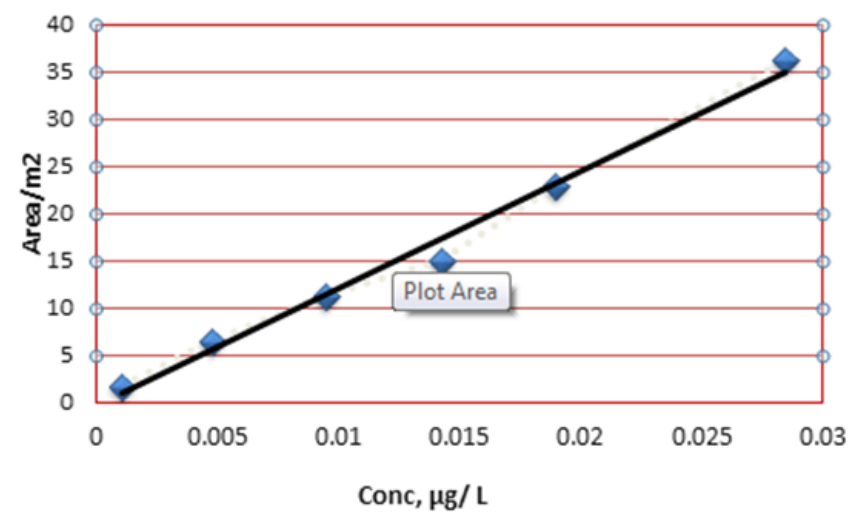

Figure 6b: Calibration plots for the determination of copper (II) with FBBT.

\section{Reproducibility}

To test the reproducibility of the present method, four repetitive analyses of each sample was studied. The RSD (\%) values for copper (II)-HNBISNH/FBBT were found to be 0.600 and 0.598 (Table 1). A $\%$ SD values obtained from the present method ranges $0.42-1.95$ as summarized in Tables 3 and 4. 
Citation: Natesh Kumar B, Kanchi S, Bisetty K, Vijaya Jyothi NV (2014) Analytical and Biological Evaluation of Two Schiff's Bases: Spectrophotometeric Analysis of Copper (II) in Water and Soil Samples. J Environ Anal Chem 1: 106. doi:10.4172/2380-2391.1000106

Page 5 of 7

\begin{tabular}{|c|c|c|}
\hline \multirow{2}{*}{ Optical Characteristics } & HNBISNH & FBBT \\
\hline & Values & Values \\
\hline Color & Orange & Brick Red \\
\hline$\lambda_{\max }[\mathrm{nm}]$ & 460 & 530 \\
\hline Stability & $30 \mathrm{~h}$ & $60 \mathrm{~h}$ \\
\hline Beer's law range $\left[\mathrm{mg} \mathrm{L}^{-1}\right]$ & $0.11-1.4$ & $0.10-1.8$ \\
\hline Molar absorptivity $\left[\mathrm{L} \mathrm{mol}^{-1} \mathrm{~cm}^{-1}\right]$ & $4.91 \times 10^{4}$ & $6.1 \times 10^{4}$ \\
\hline Sandell_s sensitivity $\left[\mu \mathrm{g} \mathrm{cm}^{-2}\right]$ & 0.0010 & 0.0014 \\
\hline \multicolumn{3}{|l|}{ Regression equation $\left(\mathrm{Y}^{\mathrm{b}}\right)$} \\
\hline Slope $^{a}$ & 0.1715 & 0.1728 \\
\hline Intercept ${ }^{b}$ & 0.0163 & 0.0152 \\
\hline Correlation coefficient [r] & 0.9994 & 0.9998 \\
\hline Relative standard deviation [\%] ${ }^{c}$ & 0.600 & 0.598 \\
\hline Range of error (95\% confidence level) & \pm 1.186 & \pm 1.044 \\
\hline Detection limit $\left[\mu \mathrm{g} \mathrm{L}^{-1}\right]$ & 0.043 & 0.036 \\
\hline$\%$ Error & 0.101 & 0.108 \\
\hline
\end{tabular}

${ }^{a}$ Experiments performed under optimized conditions (see text),

${ }^{b} Y=a x+b$, where $x$ is the concentration of analyte in $\mu \mathrm{g} \mathrm{ml}^{-1}$

${ }^{c} n=4$

Table 1: Optical characteristics for the analysis of copper (II) with HNBIFBBT using spectrophotometer.

\begin{tabular}{|l|l|}
\hline Tolerance limit/g L-1 & Interfering ions \\
\hline$>50000$ & $\mathrm{~K}(\mathrm{I}), \mathrm{Na}(\mathrm{II}), \mathrm{Ca}(\mathrm{II}), \mathrm{Mg}(\mathrm{II}), \mathrm{Al}(\mathrm{III}), \mathrm{Cr}(\mathrm{III}) \mathrm{Cl}-, \mathrm{Br}_{-}, \mathrm{PO}_{3}{ }^{3-}, \mathrm{CO}_{3}{ }^{3}, \mathrm{SO}_{4}{ }^{2-}$ \\
\hline$>10000$ & $\mathrm{Zn}(\mathrm{II}), \mathrm{Hg}(\mathrm{II}), \mathrm{NO}_{3}$ \\
\hline$>5000$ & $\mathrm{~Pb}(\mathrm{II}), \mathrm{Cd}(\mathrm{II})$ \\
\hline$>800$ & $\mathrm{Co}(\mathrm{II}), \mathrm{Ni}(\mathrm{II}), \mathrm{Fe}(\mathrm{II}), \mathrm{Fe}(\mathrm{III}), \mathrm{Mn}(\mathrm{II})$ \\
\hline
\end{tabular}

aCan be masked up to $10000 \mathrm{~g} \mathrm{~L}^{-1}$ by the addition of $2 \mathrm{~mL}$ of EDTA, thiosulfate, cyanide.

${ }^{\text {b}} \mathrm{Can}$ be masked up to $5000 \mathrm{~g} \mathrm{~L}^{-1}$ by the addition of $2 \mathrm{ml}$ of $2 \%$ citrate solution. ${ }^{\mathrm{c} C}$ Can be masked upto $800 \mathrm{~g} \mathrm{~L}^{-1}$ by the addition of $1 \%$ thiocyanate

Table 2: Tolerance limits of interfering ions on the determination of $0.2 \mu \mathrm{g} \mathrm{mL}$ ${ }^{1}$ copper (II) ion.

\begin{tabular}{|c|c|c|c|c|c|c|c|}
\hline \multirow{3}{*}{ Samples } & \multicolumn{5}{|c|}{ Present Method } & \multicolumn{2}{|c|}{ ASS Method } \\
\hline & \multicolumn{7}{|c|}{$\mathrm{Cu}$ (II) $\left[\mu \mathrm{g} \mathrm{L}^{-1}\right]$} \\
\hline & Added & Found & $\begin{array}{c}\text { Recovery } \pm \\
\text { SD }^{d}\end{array}$ & $t$-Test ${ }^{\mathrm{e}}$ & $F$-Test ${ }^{f}$ & Found & $\begin{array}{c}\text { Recovery } \pm \\
\text { SD }^{d}\end{array}$ \\
\hline \multicolumn{8}{|c|}{ Water samples } \\
\hline SWS & 2.0 & 1.98 & $97.50 \pm 0.74$ & 6.40 & 2.30 & 1.97 & $98.50 \pm 0.72$ \\
\hline NWS & - & 0.24 & - & - & - & 0.24 & - \\
\hline SWS & 3.0 & 2.94 & $98.46 \pm 0.44$ & 2.38 & 0.74 & 2.96 & $98.66 \pm 0.50$ \\
\hline NWS & - & 0.21 & - & - & - & 0.22 & - \\
\hline SWS & 4.0 & 3.92 & $98.15 \pm 0.42$ & 1.82 & 0.96 & 3.95 & $98.75 \pm 0.60$ \\
\hline NWS & - & 0.17 & - & - & - & 0.18 & - \\
\hline SWS & 5.0 & 4.96 & $99.55 \pm 0.60$ & 3.50 & 0.94 & 4.98 & $99.60 \pm 0.55$ \\
\hline \multicolumn{8}{|c|}{ Soil samples } \\
\hline SSS & 2.0 & 1.91 & $95.00 \pm 1.26$ & 3.17 & 0.64 & 1.92 & $95.50 \pm 1.28$ \\
\hline NSS & - & 0.29 & - & - & - & 0.29 & - \\
\hline SSS & 3.0 & 2.88 & $96.22 \pm 0.46$ & 4.34 & 1.32 & 2.90 & $97.10 \pm 0.64$ \\
\hline NSS & - & 0.10 & - & - & - & 0.10 & - \\
\hline SSS & 4.0 & 3.90 & $97.50 \pm 1.66$ & 2.66 & 0.87 & 3.92 & $98.00 \pm 0.98$ \\
\hline NSS & - & 0.32 & - & - & - & 0.32 & - \\
\hline SSS & 5.0 & 4.94 & $98.80 \pm 0.54$ & 1.98 & 0.40 & 4.95 & $99.00 \pm 0.89$ \\
\hline
\end{tabular}

aSamples collected around Amaraja Batteries

'Indsutrial Estate, Renigunta

'Chandragiri,

$\mathrm{d}^{\mathrm{d}}=4$

eP $\geq 0.000284$

${ }^{\mathrm{f}} \mathrm{P}=0.059$

Table 3: Analytical data for the determination of copper (II) with HNBISNH in various water and soil samples.

\begin{tabular}{|c|c|c|c|c|c|c|c|}
\hline \multirow[t]{3}{*}{ Samples } & \multicolumn{5}{|c|}{ Present Method } & \multicolumn{2}{|c|}{ ASS Method } \\
\hline & \multicolumn{7}{|c|}{$\mathrm{Cu}$ (II) $\left[\mu \mathrm{g} \mathrm{L}^{-1}\right]$} \\
\hline & Added & Found & $\begin{array}{c}\text { Recovery } \pm \\
\text { SD }^{d}\end{array}$ & $t$-Test & $F$-Test $^{f}$ & Found & $\begin{array}{c}\text { Recovery } \pm \\
\text { SD }^{d}\end{array}$ \\
\hline \multicolumn{8}{|c|}{ Water samples } \\
\hline SWS & 2.0 & 1.96 & $9.40 \pm 0.66$ & 7.00 & 2.69 & 1.97 & $99.00 \pm 0.99$ \\
\hline NWS & - & 0.23 & - & - & - & 0.24 & - \\
\hline SWS & 3.0 & 2.94 & $99.30 \pm 0.32$ & 2.66 & 0.731 & 2.96 & $99.33 \pm 0.84$ \\
\hline NWS & - & 0.20 & - & - & - & 0.22 & - \\
\hline SWS & 4.0 & 3.97 & $99.25 \pm 0.68$ & 1.90 & 1.02 & 3.98 & $99.50 \pm 0.58$ \\
\hline NWS & - & 0.20 & - & - & - & 0.21 & - \\
\hline SWS & 5.0 & 4.98 & $99.60 \pm 0.80$ & 3.85 & 0.15 & 4.99 & $99.80 \pm 0.42$ \\
\hline \multicolumn{8}{|c|}{ Soil samples } \\
\hline SSS & 2.0 & 1.94 & $98.10 \pm 1.65$ & 2.96 & 0.40 & 1.95 & $98.50 \pm 1.30$ \\
\hline NSS & - & 0.31 & - & - & - & 0.31 & - \\
\hline SSS & 3.0 & 2.95 & $98.23 \pm 0.70$ & 3.00 & 1.16 & 2.95 & $98.73 \pm 0.64$ \\
\hline NSS & - & 0.24 & - & - & - & 0.25 & - \\
\hline SSS & 4.0 & 3.95 & $99.10 \pm 1.46$ & 2.22 & 0.89 & 3.96 & $99.45 \pm 1.98$ \\
\hline NSS & - & 0.30 & - & - & - & 0.30 & - \\
\hline SSS & 5.0 & 4.99 & $99.45 \pm 0.77$ & 1.88 & 1.05 & 4.98 & $99.40 \pm 0.90$ \\
\hline
\end{tabular}

asamples collected around Amaraja Batteries,

'Indsutrial Estate, Renigunta,

chandragiri,

${ }^{\mathrm{d}} \mathrm{n}=4$,

eP $\geq 0.000284$

${ }^{\mathrm{f}} \mathrm{P}=0.05$

Table 4: Analytical data for the determination of copper(II) with FBBT in various water and soil samples.

\section{Accuracy}

The accuracy of the proposed method was evaluated by comparing the results with those obtained by the AAS method. The results showed in Tables 3 and 4 reveals that the good correlation between the two methods indicative of present method was almost sensitive to that of AAS method.

\section{Detection limit}

Under optimized conditions the detection limit for determination of copper (II) by using present method (signal to noise ratio $=2$ ) was $0.043 \mu \mathrm{g} \mathrm{L} \mathrm{L}^{-1}$ and $0.036 \mu \mathrm{g} \mathrm{L}{ }^{-1}$ with HNBISNH and FBBT respectively.

\section{Analytical applications}

The present method was applied to the determination of copper (II) in different water and soil samples using new synthesis ligands, HNBISNH/FBBT. This method was comparable with the standard AAS method in terms of students' $t$ ' test and ' $f$ test as shown in Tables 3 and 4 . The analytical data summarized in Tables 3 and 4 suggest that the percentage of copper (II) recovery from water and soil samples ranges from 96.00 to $99.80 \%$ which is more reliable and sensitive than the other methods. The recovery percentage of the copper (II) represented in the Tables 3 and 4 indicates that their order in various environmental systems under study are as follows:

Water samples with FBBT $>$ Water samples with HNBISNH

Soil samples with FBBT> Soil samples with HNBISNH

It is evident from the previous data that the proposed method was simple, rapid and sensitive for the determination of copper (II) in different samples of environmental importance. The results 
Citation: Natesh Kumar B, Kanchi S, Bisetty K, Vijaya Jyothi NV (2014) Analytical and Biological Evaluation of Two Schiff's Bases: Spectrophotometeric Analysis of Copper (II) in Water and Soil Samples. J Environ Anal Chem 1: 106. doi:10.4172/2380-2391.1000106

Page 6 of 7

showed that the calculated values (Tables 3 and 4) did not exceed the theoretical values. Therefore, there is no significant difference between the proposed and the standard method, indicating that the developed method is as accurate and precise as the standard AAS method.

\section{Biological activity of the complexes}

Antibacterial activity of copper (II)-HNBISNH/FBBT synthesized complexes were studied against the gram positive bacteria (Bacillus subtillis and Staphylococcus aureus) and gram negative bacteria (Escherichia coli and Pseudomonas aeruginosa) at a concentration of $10 \mu \mathrm{g} \mathrm{mL} \mathrm{m}^{-1}$ by disc diffusion method. The antibacterial activity was more effective with copper (II)-FBBT synthesized complex with $23.2 \mathrm{~mm}$ to $16.5 \mathrm{~mm}$ Inhibition Zone than copper (II)-HNBISNH synthesized complex with an inhibition zone of 17.5 to $14.2 \mathrm{~mm}$; the antibacterial activity of both the complexes was more when compared to that of the control Gentamycin - Standard with $9.33 \mathrm{~mm}$ to $12.26 \mathrm{~mm}$ Inhibition Zone. In this experiment, copper (II)-HNBISNH synthesized complex, S.aureus shows more activity with an inhibition zone of $17.5 \mathrm{~mm}$ followed by P.aeruginosa $(16.4 \mathrm{~mm})$, E.coli $(15.2 \mathrm{~mm})$ and B.subtilis (14.2 mm). In case of copper (II)-FBBT synthesized complex, B.subtilis shows effective antibacterial activity with an inhibition zone of $23.2 \mathrm{~mm}$; S.aureus $22.5 \mathrm{~mm}$ and Escherichia coli $18.3 \mathrm{~mm}$; followed by P.aeruginosa $16.5 \mathrm{~mm}$. Therefore, the antibacterial activity of the synthesized complexes of copper (II)-HNBISNH, copper (II)FBBT and control was in the order of copper (II)-FBBT complex > copper (II)-HNBISNH complex $>$ Control as shown in Table 5. Both the ligands show Minimum Inhibitory Concentrations at very low concentrations against all pathogens ranging between 0.078 to 1.25 $\mathrm{mg}$. The least concentration was against Bacillus subtilis with copper (II)-FBBT synthesized complex all the results are shown in Figure 7. Therefore the present findings may also be open a new search for the complexes for use in bacterial diseases.

\begin{tabular}{|l|c|c|c|}
\hline \multirow{2}{*}{ Organism } & \multicolumn{2}{|c|}{$\begin{array}{c}\text { Antimicrobial activity(IZ } \\
\text { diameter in } \mathbf{~ m m} \text { ) }\end{array}$} & $\begin{array}{c}\text { Control } \mathbf{1 0} \mathbf{\mu g} / \mathbf{~ d i s c} \\
\text { disc }\end{array}$ \\
\cline { 2 - 4 } & $\begin{array}{c}\text { Cu(II)-HNBISNH } \\
\text { complex* }\end{array}$ & $\begin{array}{c}\text { Cu (II)-FBBT } \\
\text { complex* }\end{array}$ & Gentamycin \\
\hline Bacillus subtilis & $14.2 \pm 0.14$ & $23.2 \pm 0.09$ & $11.76 \pm 0.555$ \\
\hline Staphyloccocus aureus & $17.5 \pm 0.16$ & $22.5 \pm 0.04$ & $9.33 \pm 0.471$ \\
\hline Escherichia coli & $15.2 \pm 0.16$ & $18.3 \pm 0.12$ & $9.33 \pm 0.235$ \\
\hline Pseudomonas aeruginosa & $16.4 \pm 0.16$ & $16.5 \pm 0.16$ & $12.26 \pm 0.188$ \\
\hline
\end{tabular}

IZ = inhibition zone, *Standard Deviation, \pm Mean of Triplicates

Table 5: Results of the antibacterial activity of the synthesized complexes in $\mathrm{mm}$.

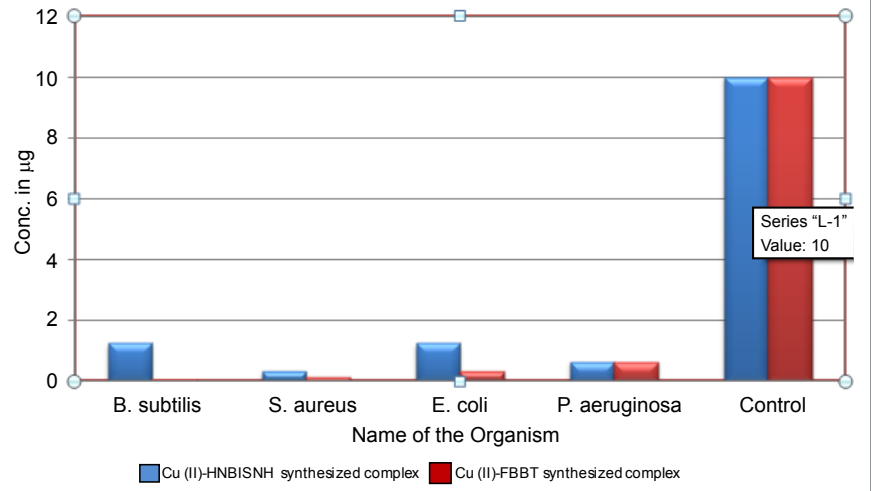

Figure 7: Minimum Inhibitory Concentration in $\mu \mathrm{g}$

\section{Conclusion}

In this present investigation, evaluation of two ligands, HNBISNH and FBBT were successfully study the analytical performance (complex affinity) experimentally. Due to the high complexing ability of the ligands, the developed analytical method/applications for the determination of copper (II) become facile, sensitive, rapid and selective. This non-extractive spectrophotomeric method is ecofriendly and effectively applied to analyze copper (II) in different water and soil samples. Moreover, antibacterial activity copper (II)-FBBT synthesized complex was greater than that of copper (II)-HNBISNH. This antibacterial activity facilitates the biological importance of the synthesized ligands to control diseases effectively.

\section{Acknowledgements}

BNK is grateful for the financial support provided by the University Grant Commission, New Delhi, India in the form of JRF-BSR fellowship to carry out this work. One of the authors is highly thankful to the Department of Botany, S.V. University, India for biological evaluation of the compounds and complexes.

\section{References}

1. Barnaby JF (2008) Regulators Stamp Copper as a Germ Killer,New York Times.

2. Los Alamos National Laboratory-Copper.

3. Saker B, Haussac JP, Hau S (1983) Transport forms of copper in human serum. Biological Aspects of Metal and Metal-Related Diseases, Revan Press, New York.

4. Seudeal ND, Thibert RJ, Zak B (1986) Sequential determination of iron, copper and zinc in a single aliquot using 2-amino-5-bromopyridylazo resorcinol. Microchem J 34: 131-139.

5. Hejazi L, Mohammadia DE, YaminiY, Brereton RG (2004) Solid-phase extraction and simultaneous spectrophotometric determination of trace amounts of $\mathrm{Co}, \mathrm{Ni}$ and $\mathrm{Cu}$ using partial least squares regression, Talanta 62 183-189.

6. Thakur M1, Deb MK (1999) The use of 1-[pyridyl-(2)-azo]-naphthol-(2) in the presence of TX-100 and N, N'-diphenylbenzamidine for the spectrophotometric determination of copper in real samples. Talanta 49: 561-569.

7. Niazi A, Yazdanipour A (2008) Simultaneous spectrophotometric determination of cobalt, copper and nickel using 1-(2-thiazolylazo)-2-naphthol by chemometrics methods. Chin ChemLett 19: 860-864

8. Gao HW (2000) Investigation of properties of copper, ferrous complexes with 1-(5-bromo-2-pyridylazo)-2-naphthol-6-sulphonic acid and application of substitution reaction in metallic complex to selective determination of trace amounts of metal. Talanta 52: 817-823.

9. Sharma AK, Singh I (2009) Trace determination ofcopper in foodstuffs and biological samples. Anal Lett 42: 1527-1538.

10. Gaber M, El-Baradie KY, El-Sayed YS (2008) Spectral and thermal studies of 4-(1H-pyrazolo (3,4-d) pyrimidin-4-ylazo) benzene-1,3-diol complexes of cobalt(II), nickel(II) and copper(II). SpectrochimActa A MolBiomolSpectrosc 69: 534-541.

11. Salillas M, Tarin P, Blanco M (1985) Extractive-spectrophotometric determination of traces of copper with 4-(p-nitrophenylazo)-2-amino-3pyridinol.Microchem J 31: 61-69.

12. Singh I, MrsPoonam, Kadyan PS (1985) Spectrophotometric determination of iron and copper in milk, foodstuffs and body tissues with 1-(2-quinolylazo)2,4,5-trihydroxybenzene. Talanta 32: 387-390.

13. Yuan L, Huo SH, Ren XN, Chen H (2008) A novel spectrophotometric determination of copper(II) with bromosulphonazo III. Chin Chem Lett 19: 9294.

14. Panahi HA, Karmi M, Moniri E, Soudi H (2008) Development of a sensitive spectrophotometric method for determination of copper. African J Pure ApplChem 2: 96-99.

15. Alexaki-Tzivanidou H, Vasilikiotis GS (1981) Spectrophotometric study of the copper(II)-2,2'-dipyridyl-2-pyridylhydrazone complex formation, Microchem J 26: $1-9$. 
Citation: Natesh Kumar B, Kanchi S, Bisetty K, Vijaya Jyothi NV (2014) Analytical and Biological Evaluation of Two Schiff's Bases: Spectrophotometeric Analysis of Copper (II) in Water and Soil Samples. J Environ Anal Chem 1: 106. doi:10.4172/2380-2391.1000106

Page 7 of 7

16. Guzar SH, Jin QH (2008) Simple, selective, and sensitive spectrophotometric method for determination of trace amounts of nickel(II),copper(II), cobalt(II), and iron(III)with a novel reagent 2-pyridine carboxaldehydeisonicotinylhydrazone, Chem Res Chinese Uni 24: 143-147.

17. Goyal N, Purohit PJ, Page AG, Shastry MD (1992) Direct determination of beryllium, copper and zinc in AlU matrices by electrothermal atomization atomic-absorption spectrometry. Talanta 39:775-778

18. Van Veen EH, De Loss-Vollebergt MTC, Wassink AP, Kalter H (1992) Anal Chem 64: 1643

19. Lobinski R, Van Borm W, Broekaert JAC, Tschöpel P, Tölg G (1992)Optimation of slurry nebulization inductively coupled plasma atomic emission spectrometry for the analysis of ZrO, 2 powder. Fresenius J Anal Chem342: 563-568.
20. Brown L, Hacwell SJR, Head MM, Neill PO (1983) Bancroft, K.C.C, Analyst 108:1511.

21. Allen AF, Bartlett PKN (1984)Ingrom G Analyst 109: 1075.

22. National Committee for Clinical Laboratory Standards (1993) Methods for dilution antimicrobial susceptibility tests for bacteria that grow aerobically, third ed., Approved standard M7- A3. NCCLS, Villanova, Pa.

23. Vollekova AD, Ova K,Sochorova $R$ (2001) Isoquinoline Alkaloids from Mahoniaaquifolium stem bark is active against Malassezia sp. Folia. Microbiol Warangal, Andhra Pradesh, India. Ethnobotanical Leaflets, 14: 361-365.

24. Usman H, Abdulrahman FL, Ladam AH (2007) Phytochemical and Antimicrobia Valuation of Tribulusterrestris L. (Zygophyllaceae) growing in Nigeria. Res JBio Sci 2: 244-247

25. Jacson ML (1965) Soil chemical analysis. Prentice Hall, Englowed Cliffs, NJ. 